\title{
Effect of Preparation Method on the Electrical and Mechanical Properties of PVC/Carbon Nanotubes Nanocomposites
}

\author{
Leticia Trezecik Silvano ${ }^{a}{ }^{\circledR}$, Atilio Luiz Vittorazzo Jr. ${ }^{b}$, Rogerio Gomes Araujo ${ }^{a, b *}$ \\ ${ }^{a}$ Centro Universitário SOCIESC - UNISOCIESC, Departamento de Engenharia Química, Campus Boa \\ Vista, Rua Albano Schmidt, 3333, 89206-001, Joinville, SC, Brasil \\ ${ }^{b}$ Centro Universitário SOCIESC - UNISOCIESC, Programa de Mestrado em Engenharia Mecânica, \\ Campus Boa Vista, Rua Albano Schmidt, 3333, 89206-001, Joinville, SC, Brasil
}

Received: December 12, 2017; Revised: March 28, 2018; Accepted: June 25, 2018

\begin{abstract}
The biggest challenge for the development of carbon nanotubes polymeric nanocomposites is in the suitable dispersion and distribution of the nanometric particles along the polymer matrix. Several preparation methods have been used to obtain nanocomposites, highlighting the mixture with polymer solution followed by solvent evaporation and the hot compacting. The first one has the advantage of allowing dispersion of the nanotubes in a low viscosity medium, while the second method is more environmental favorable due to reduced use of solvent. The aim of this work was to evaluate the influence of the preparation method on the electrical resistivity of PVC/carbon nanotubes nanocomposites, containing from 0.05 to $1.00 \% \mathrm{w}$ of carbon nanotubes. The results showed a percolation threshold of $0.4 \% \mathrm{w}$ and $0.15 \% \mathrm{w}$ of nanotubes for the polymer solution method and hot compacting, respectively, and an electrical resistivity reduction of eight and nine orders of magnitude, respectively, compared to pure PVC. The tensile strength of PVC/MWNT nanocomposites was not affected by the presence or content of carbon nanotubes compared to PVC without addition of nanoparticles, regardless of the material preparation method, however the deformation at beak was largely reduced.
\end{abstract}

Keywords: Carbon nanotubes, PVC, electrical resistivity, mechanical properties.

\section{Introduction}

Polymeric nanocomposites have attracted great interest in scientific community since the physical properties of the matrix polymer are significantly altered by the addition of nanoparticle amounts of less than $1 \% \mathrm{~m}^{1-7}$. Carbon nanotubes are tubular carbon nanoparticles with one or more cylindrical layers of graphene, resulting in single wall (SWNT) and multiple wall (MWNT) nanotubes, respectively. The graphene structure confers remarkable properties for carbon nanotubes, such as thermal and electrical conductivity, mechanical and chemical resistance. In addition, the low specific weigth, the nanometric dimensions and the high aspect ratio (ratio between length and diameter) of the particles make the nanotubes advantageous for applications that require high specific surfaces, such in the case of reinforcing agents in materials composites.

Poly (vinyl chloride) - PVC is the third most widely used polymer in the world, below polyethylene and polypropylene, only. In 2016, over 42 million tonnes of PVC were consumed, corresponding to over $16 \%$ of total plastics demand ${ }^{8}$. The low cost, chemical stability, mechanical and weather resistance and the ability to absorb additives, which improve their properties, are fundamental characteristics that justify such large consumption of this polymer. The largest field of PVC application is in civil construction, mainly in pipes, electro ducts, window profiles, plates and electrical cable cladding 9 . On the other hand, PVC has great potential for applications in electrical and electronic devices due to its natural flame retardancy, but for use as a barrier against electromagnetic interference (EMI shielding), the electrical conductivity of the polymer needs to be improved.

The biggest challenge for the effective use of carbon nanotubes in polymer matrix composites lies in the homogeneous dispersion or distribution of the nanoparticles along the continuous phase. The performance of the nanocomposites depends on the degree of dispersion, the orientation of the nanotubes and the nanotube/polymer surface interaction. Therefore, the disentanglement of carbon nanotubes prior to the composites preparation process is recommended because, depending on the Van der Waals interactions between them, the carbon nanotubes intertwine forming micro or macroscopic aggregates. Therefore, the method used to prepare the nanocomposites should be able to eliminate the aggregates formed by the entanglement of the nanotubes, promoting the uniform distribution of the nanoparticles along the matrix.

Several nanocomposites preparation methods are known, with emphasis on polymer melt mixing, polymer solution mixing, in situ polymerization and mixing by hot compacting. 
Polymer solution mixing method consists in promoting the dispersion of the carbon nanotubes in a solution of matrix polymer with the aid of mechanical agitation and mainly ultrasonication followed by casting and solvent evaporation ${ }^{10}$. The great advantage of this method is the capability to nanoparticles dispersion due to the low viscosity of the solution. The use of large amounts of solvent and the need of its subsequent elimination are the major disadvantages of this method. On the other hand, by hot compacting method the nanocomposites are obtained through the dry mixing of polymer and nanoparticles powders followed by hot pressing. This method has the advantage of using a smaller amount of solvent, being suitable for industrial scale expansion.

In this work, PVC/MWNT nanocomposites with nanoparticle contents between 0.05 and $1.00 \% \mathrm{w}$ were produced using the methods of polymer solution mixing and hot compacting to evaluate the influence of the preparation method on the volumetric electrical resistivity and tensile properties. Thermogravimetric analyzes were performed on the components of the PVC compound (matrix) used in the hot compacting method to characterize the behavior of each of them during the nanocomposite preparation process.

\section{Experimental}

\subsection{Materials}

For the nanocomposites preparation, multiwalled carbon nanotubes (MWNT) of NC7000 mark, supplied by Nanocyl (Sambreville, Belgium), were used. These conductive nanoparticles are produced by CVD method with an average diameter of $9.5 \mathrm{~nm}$ and an average length of $1.5 \mu \mathrm{m}$, presenting a surface area of $250-300 \mathrm{~m}^{2} \mathrm{~g}^{-1}$ and a volumetric resistivity of $10^{-4} \Omega \mathrm{cm}$, according to supplier.

As the polymer matrix of composites, the polyvinyl chloride (PVC) NORVIC SP1000 produced by Braskem S.A. was utilized. The PVC, synthesized by suspension polymerization, was used in the powder form with particles size between 63 and $250 \mu \mathrm{m}$ and $\mathrm{K}$-factor of 65 . For the hot compacting method, a PVC compound was previously prepared using the following additives: Dioctyl phthalate - DOP(INBRACIZER-10 supplied by Inbra) as a plasticizer, calcium and zinc based thermal stabilizer (Naftosafe supplied by Chemson) and stearic acid (supplied by Chemson) as a lubricant.

\subsection{Preparation of composites}

The PVC/MWNT nanocomposites with carbon nanotubes content of $0,05,0,10,0,15,0,20,0,30,0,50,0,70$ and 1,00 $\% \mathrm{w}$ were obtained using the hot compacting method. A rigid PVC compound, which formulation is presented in Table 1, was prepared by intensive mixing (dry blend). The MWNT was previously suspended in ethanol and ultrasonicated during $15 \mathrm{~min}$ to pre-dispersion of nanoparticles. The sonicated MWNT and PVC compound were mixed in a porcelain mortar to the visually homogeneous state. After ethanol evaporation, the homogenized mixture was transferred to a hydraulic press and compacted between two steel plates heated at $170{ }^{\circ} \mathrm{C}$ and then pressed during $15 \mathrm{~min}$ at $19 \mathrm{MPa}$. The specimens, in a plate shape of $1,0 \mathrm{~mm}$ thickness, were demolded after cooling up to room temperature.

Table 1. The PVC compound formulation.

\begin{tabular}{lc}
\hline Component & Amount $(\% \mathrm{w})$ \\
\hline PVC & 81,7 \\
DOP & 9,8 \\
Naftosafe & 6,5 \\
Stearic acid & 2,0 \\
Total & 100 \\
\hline
\end{tabular}

The process parameters of the hot compaction method were defined after several tests using PVC without addition of carbon nanotubes, varying time, temperature and pressure. Although the PVC compound contains a large amount of thermal stabilizer (well above the percentage used in extrusion, for example), the samples obtained by compaction at temperatures above $170{ }^{\circ} \mathrm{C}$ and/or times above $15 \mathrm{~min}$ showed yellowing, indicating the degradation of the polymer.

On the other hand, PVC/MWNT nanocomposites with carbon nanotubes content of $0,20,0,30,0,40,0,60,0,80$ and $1,00 \% \mathrm{w}$ were obtained using the polymer solution mixing method. The MWNTs were suspended in $5 \mathrm{ml}$ of tetrahydrofuran (THF) and homogenized in an ultrasound bath for $15 \mathrm{~min}$ to break up the bundles. Then, the suspension was mixed with $25 \mathrm{ml}$ of PVC/THF solution $(6 \% \mathrm{w} / \mathrm{v})$. The final mixture was then homogenized by mechanical stirring for $15 \mathrm{~min}$ and bath ultrasonication for another 15 min, alternately, completing three cycles. At the end of the nanotubes dispersion process, the mixture was transferred to a flat glass mold for solvent evaporation at room temperature for $24 \mathrm{~h}$. The thin film with thickness of about $100 \mu \mathrm{m}$ was then demolded and placed into vacuum oven at $90^{\circ} \mathrm{C}$ for 48 $\mathrm{h}$ for additional solvent removal.

\subsection{Raw Materials and Nanocomposites Characterization}

Thermogravimetric analysis (TG) was performed to evaluate the loss of mass resulting from the heating of PVC compound components samples (polymer and additives), used in the hot compacting method. The objective of this analysis was to characterize the thermal decomposition or volatilization profile of the each component to predict the PVC compound behavior, during the hot compacting process. The measurements were performed using a TA Instruments TGA-Q50. The samples of about $10 \mathrm{mg}$ were heated at $10^{\circ} \mathrm{C}$ $\mathrm{min}^{-1}$ from room temperature to $700^{\circ} \mathrm{C}$, under a synthetic

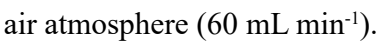


The volume resistivity was measured directly on the composites samples obtained by the both preparation processes, following the 2-point method. A Keithley electrometer Model 6517A equipped with 8009 High Resistance Test Fixture was used, applying a voltage of 10 Volt and measuring the electric current ${ }^{11}$.

Tensile properties of PVC and PVC/MWNT composites were obtained based on ASTM D882-12 method. Test specimens in the shape of rectangular strips of $100 \mathrm{~mm}$ length (gauge length of $50 \mathrm{~mm}$ ) and $11 \mathrm{~mm}$ of width were submitted to the test. The tensile tests were performed using an EMIC DL-30000 test machine, equipped with $500 \mathrm{kgf}$ load cell, at a crosshead speed of $5.0 \mathrm{~mm} \mathrm{~min}^{-1}$. Tensile strength, and elongation at break of each sample were obtained based on at least five specimens per sample.

\section{Results and Discussion}

Figure 1 presents the results of the thermogravimetric analysis of the PVC compound, used as the matrix of the PVC/MWNT nanocomposites obtained by the hot compacting method, in comparison with its components. The weight loss behavior of PVC (SP-1000) occurred in two distinct stages, according to $\mathrm{Yu}$ and collaborators ${ }^{12}$. The first stage started at about $250{ }^{\circ} \mathrm{C}$ and is attributed to the polymer dehydrochlorination and formation of a linear polyene structure, while the second stage occurred from $450{ }^{\circ} \mathrm{C}$ and refers to the rupture of the double bonds of the polyene structure forming volatile hydrocarbons. A similar weight loss behavior is observed in the analysis of the PVC compound, although the overlap of the weight loss of the other additives is clear.

Table 2 summarizes the results corresponding to the first step of weight loss for the PVC compounds and its components: the weight loss percentage $(\Delta \mathrm{W})$, the initial and final temperature $\left(\mathrm{T}_{\mathrm{i}}-\mathrm{T}_{\mathrm{f}}\right)$ and the temperatures of maximum weight loss rate $\left(\mathrm{T}_{\max }\right)$. The stearic acid presented thermal decomposition between 150 and $265^{\circ} \mathrm{C}$, while the DOP decomposed between 170 and $293^{\circ} \mathrm{C}$. It is assumed that the mass loss of stearic acid and DOP is attributed to thermal decomposition, since the boiling temperatures of these compounds are 383 and $370{ }^{\circ} \mathrm{C}$, respectively. The thermogravimetric analysis made under synthetic air atmosphere led the compounds to thermal decomposition due to the presence of oxygen.

The Naftosafe thermal stabilizer, composed by calcium and zinc stearates, presented mass loss in two stages: the first stage between 170 and $345^{\circ} \mathrm{C}$ and the second stage between 400 and $490^{\circ} \mathrm{C}$. This result agrees with Xu et al. ${ }^{13}$, confirming the composition of the stabilizer.

It could be observed that the $\mathrm{T}_{\max }$ of PVC compound occurred at lower values of temperature than pure PVC. This behavior was also observed by $\mathrm{Xu}$ et al. ${ }^{11}$ for PVC stabilized with stabilizers containing zinc ions. The relative lower decomposition temperature of this kind of PVC compound could be attributed to the generation of $\mathrm{ZnCl}_{2}$ which can catalyze the decomposition of PVC due to its strong Lewis acidity. The mass loss initial temperature of the PVC compound is $165^{\circ} \mathrm{C}$, but this mass loss is relative to the thermal decomposition of DOP and stearic acid. The PVC degradation occurs above $230^{\circ} \mathrm{C}$ indicating that the temperature of $170^{\circ} \mathrm{C}$, employed in the hot compacting method, is suitable to keep the integrity of the polymer.

The volumetric electrical resistivity behavior of the PVC/MWNT nanocomposites, obtained by the two preparation methods, as a function of the carbon nanotube content is presented in Figure 2. An eight and nine orders of magnitude reduction in electrical resistivity were observed in the nanocomposites obtained by polymer solution mixing and hot compacting methods, respectively. However, the percolation threshold found in the hot compacting method was $0.15 \% \mathrm{w}$, significantly lower than that found in the solution mixing method, which was $0.40 \% \mathrm{w}$. Such behavior agrees with the results of Mamunya et al. ${ }^{1}$ and Araújo ${ }^{10}$ and is due to the establishment of a three-dimensional conductive network of nanotubes in the nanocomposites obtained by the hot compacting method. In the polymer solution mixing method, despite better dispersion conditions of the carbon
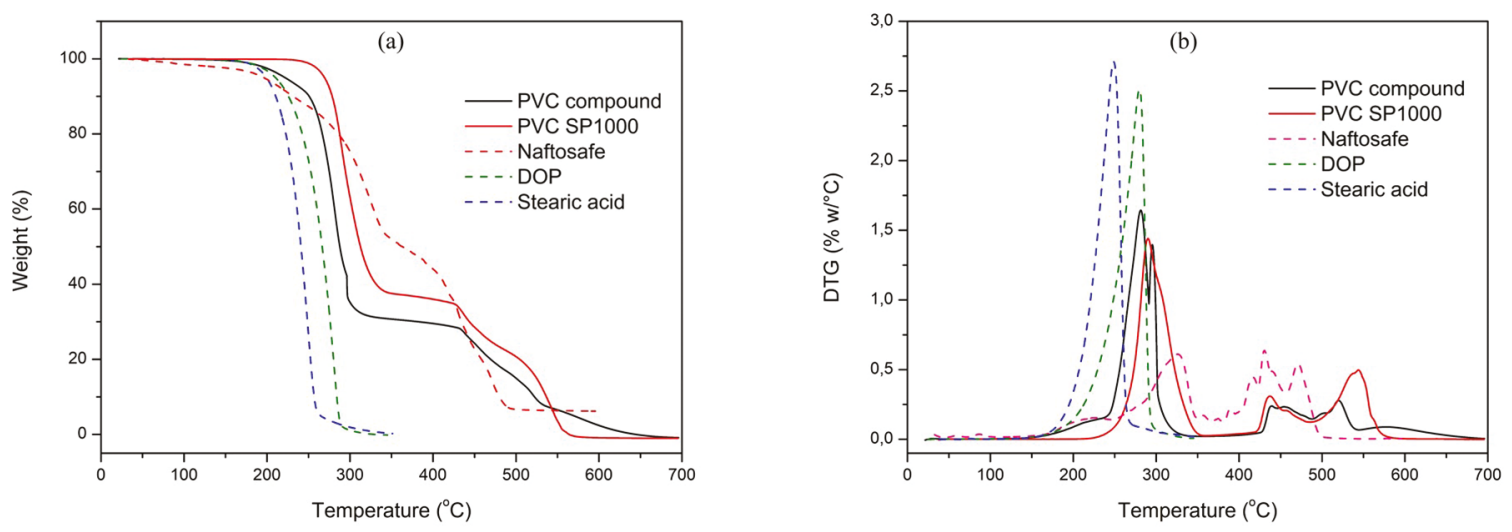

Figure 1. TG (a) and DTG (b) curves of PVC compound and its components 
Table 2. TG results of the PVC compound and its components corresponding to the first stage of mass loss

\begin{tabular}{lccc}
\hline Material & $\Delta \mathrm{W}(\%)$ & $\mathrm{T}_{\mathrm{i}}-\mathrm{T}_{\mathrm{f}}\left({ }^{\circ} \mathrm{C}\right)$ & $\mathrm{T}_{\max }\left({ }^{\circ} \mathrm{C}\right)$ \\
\hline PVC Compound & 69.0 & $165-345$ & 281.4 \\
PVC SP1000 & 62.6 & $225-350$ & 290.0 \\
Naftosafe & 41.0 & $160-345$ & 325.8 \\
DOP & 100.0 & $150-295$ & 279.6 \\
Stearic acid & 100.0 & $150-265$ & 248.6 \\
\hline
\end{tabular}

nanotubes, a greater amount of nanoparticles is necessary for percolation, since nanotubes tend to agglomerate during the solvent evaporation step. Yazdani $\mathrm{H}$ et al. ${ }^{14}$ also determined a percolation threshold between 0,2 and 0,4\%w for composites MWNT/plasticized PVC obtained by nanoparticles dispersion with sonication probe. The authors affirmed that as the carbon nanotubes content exceeds the percolation threshold, the composite enters the percolation region across which a transition takes place in the nature of charge transport from tunneling to partial metallic diffusive transport. They determined the volumetric electrical resistivity of $10^{7} \Omega \mathrm{cm}$ (electrical conductive $=10^{-5} \mathrm{~S} / \mathrm{m}$ ) for composites with $1,0 \% \mathrm{w}$ MWNT, the same value determined in this work for composite prepared by polymer solution mixing. On the other hand, Wang et al. ${ }^{15}$ reported lower values of electrical resistivity of MWNT/PVC composites obtained by mixing in solution: $10^{5}$ and $10^{4} \Omega \mathrm{cm}$ for composites containing, respectively, 0.7 and $1.0 \% \mathrm{w}$ of nanotubes. This difference in resistivity of the materials compared to that achieved in this work may be a consequence of the different nanotubes dispersion conditions by the authors.

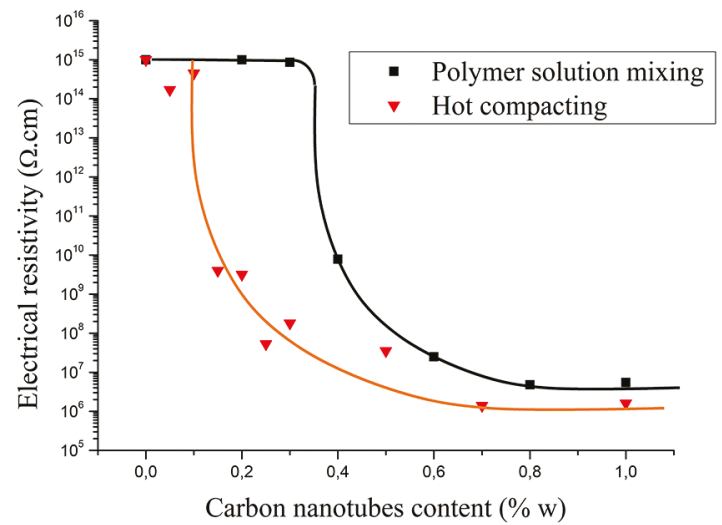

Figure 2. Volumetric electrical resistivity behavior of PVC/MWNT nanocomposites related to carbon nanotubes content

The tensile strength of the PVC/MWNT nanocomposites, obtained by the solution-mixing method, keeps practically unchanged compared to PVC without addition of carbon nanotubes, for all formulations studied as shown in Figure 3. On the other hand, the deformation at break was drastically reduced in all nanocomposites formulations. This behavior suggests that the dispersion of the nanoparticles was not adequate, resulting in the formation of carbon nanotube aggregates that induce the formation of cracks in the material and premature rupture during the tensile test. The presence of the nanotube aggregates does not interfere in the tensile strength of the material, since the maximum stress of both the PVC and the nanocomposites occurs at the yield limit and is associated with the elastic deformation, in which the deformation values are low. The effect of crack induction by the presence of carbon nanotubes aggregates occurs after the yield limit, associated to plastic deformation, in which the test specimens are subjected to greater deformations with consequent interference of the aggregates in the viscous flow of the polymer chains. Similar results were found by Yazdani $\mathrm{H}$ et al. ${ }^{14}$ who studied composites of MWNT dispersed in plasticized PVC matrix. These authors concluded that a thoroughly well-dispersed filler in a polymer matrix slightly improves its tensile strength. On the other hand, the presence of the nanotubes significantly reduces the deformation at break of the nanocomposites in comparison to the unmodified polymer. They found a reduction of 3 times in deformation at break, from $450 \%$ for unmodified PVC to $150 \%$ for composite with $0,5 \%$ MWNT, while in this work a larger reduction of 4 times was observed. However, this larger reduction can be attributed to the brittleness of rigid PVC matrix of this work in comparison with plasticized PVC matrix of Yazdani composites.

On the other hand, Zanjanijam et al. ${ }^{16}$ observed a progressive increase in the tensile strength of SWNT/PVC composites as the nanotube content was increased from 0,25 to $0.75 \%$, however in composites with higher nanotube contents the tensile strength was practically the same as PVC unmodified. The authors attributed this increase in tensile strength to the adequate dispersion of the nanotubes in the polymer matrix in composites containing up to $0.75 \%$ of nanoparticles, however the poor dispersion of higher nanotube contents maintains the tensile strength unchanged in relation to the isolated polymer. Mkhabela et al. ${ }^{17}$ studied MWNT/ PVC composites obtained by melt mixing and concluded that as the composites became stiffer because the addition of carbon nanotubes, they turned more brittle, therefore getting easily fractured.

PVC/MWNT nanocomposites obtained by hot compacting method showed similar behavior in relation to the tensile strength, as shown in Figure 4. The tensile strength of the nanocomposites remained practically unchanged compared to PVC without addition of carbon nanotubes. However, extremely low values of deformation at break were observed in all nanocomposites and PVC without addition of nanotubes. This result indicates that the process conditions employed in the hot compacting method were insufficient for the total melting of the PVC particles, preventing the polymer molecular diffusion between them. The reduction of the 

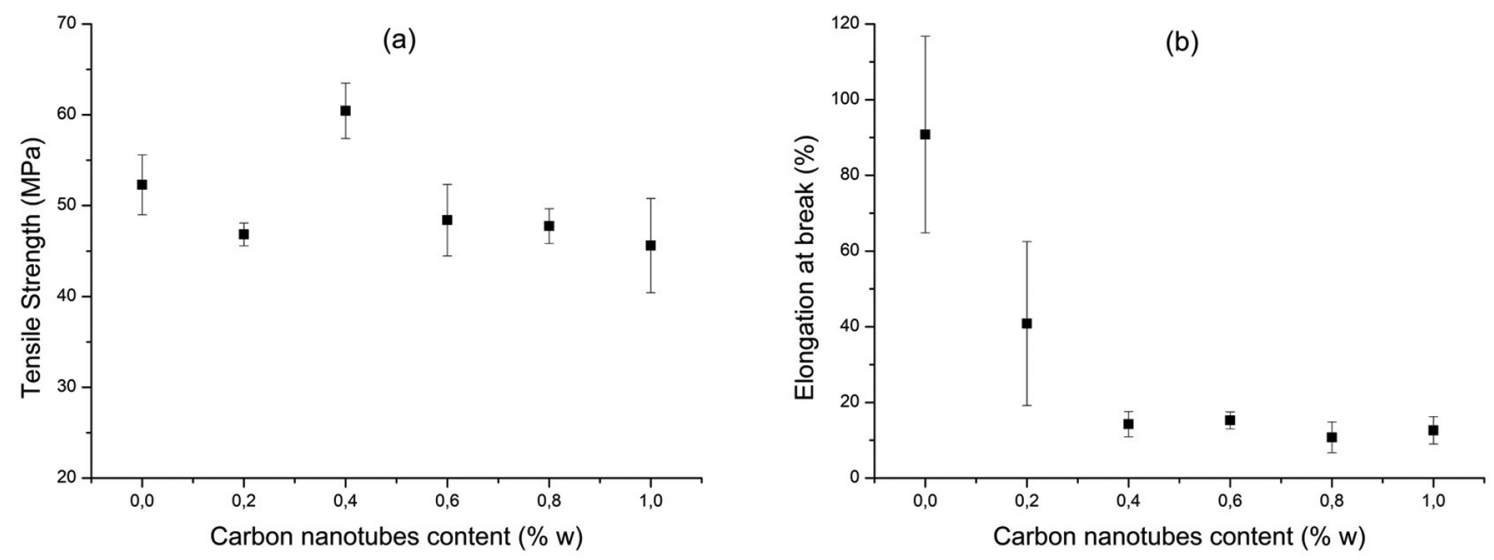

Figure 3. Tensile strength (a) and deformation at break (b) behavior of PVC/MWNT nanocomposites obtained by solution mixing method related to carbon nanotubes content
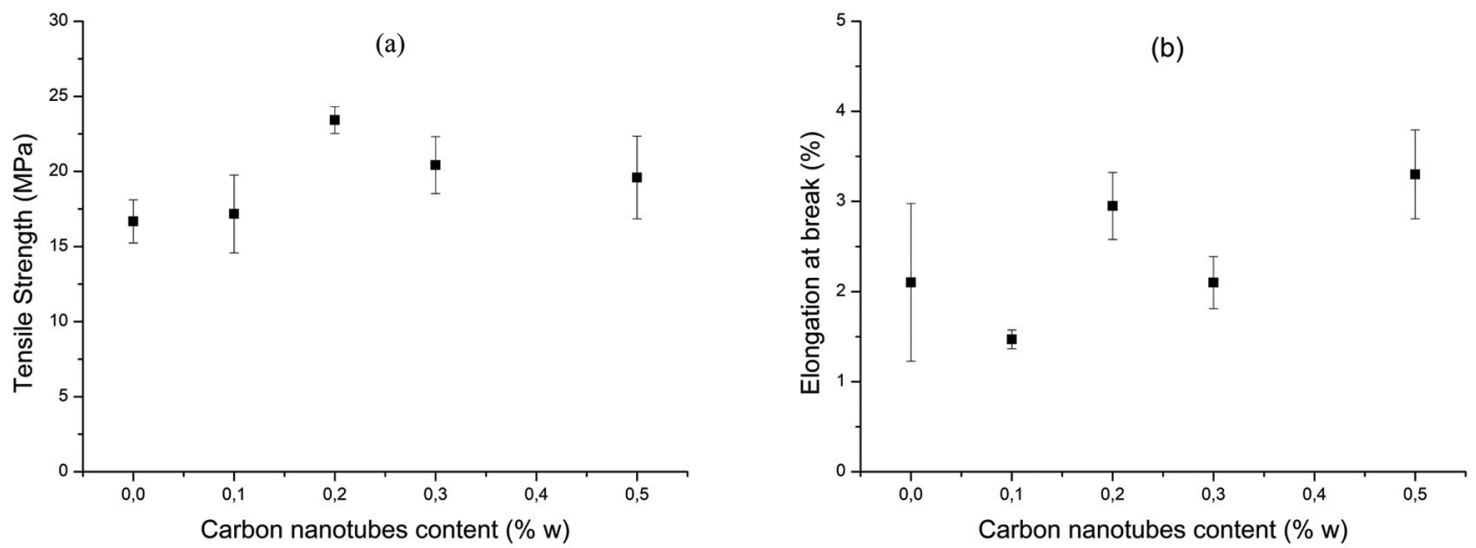

Figure 4. Tensile strength (a) and deformation at break (b) behavior of PVC/MWNT nanocomposites obtained by hot compacting method related to carbon nanotubes content

tensile strength of the PVC without addition of nanotubes, in relation to PVC obtained in the solution mixing method, was expected and is due to the presence of the DOP as a plasticizer in the PVC compound used in this method.

\section{Conclusions}

The preparation method influenced the behavior of the electrical resistivity of the PVC/MWNT nanocomposites, since the percolation threshold observed in the hot compacting method was $0.15 \% \mathrm{w}$, significantly lower than that found in the solution mixing method, which was $0.40 \% \mathrm{w}$. In addition, the electrical resistivity reduction was nine orders of magnitude for the nnaoocomposites obtained by hot compacting and eight orders of magnitude for the solution mixing method, in the studied carbon nanotubes contents.

The tensile strength of PVC/MWNT nanocomposites was not affected by the presence or content of carbon nanotubes compared to PVC without addition of nanoparticles, regardless of the material preparation method. On the other hand, the deformation at beak was largely reduced in the nanocomposites obtained by the solution mixing method, indicating the presence of carbon nanotube aggregates. The hot compacting method requires adjustments in the process conditions for a better mechanical performance of the obtained materials, although in relation to the electrical properties it has been shown more suitable.

\section{References}

1. Mamunya YP, Levchenko VV, Rybak A, Boiteux G, Lebedev EV, Ulanski J, et al.Electrical and thermomechanical properties of segregated nanocomposites based on PVC and multiwalled carbon nanotubes. Journal of Non-Crystalline Solids. 2010;356(11-17):635-641. DOI: http://dx.doi.org/10.1016/j. jnoncrysol.2009.09.038

2. Loos MR, Coelho LAF, Pezzin SH, Amico SC. Effect of carbon nanotubes addition on the mechanical and thermal properties of epoxy matrices. Materials Research. 2008;11(3):347-352. DOI: http://dx.doi.org/10.1590/S1516-14392008000300019 
3. Patti A, Barretta R, de Sciarra FM, Mensitieri G, Menna C, Russo P. Flexural properties of multi-wall carbon nanotube/ polypropylene composites: Experimental investigation and nonlocal modeling. Composite Structures. 2015;131:282-289. DOI: http://dx.doi.org/10.1016/j.compstruct.2015.05.002

4. Granados-Martínez FG, Domratcheva-Lvova L, Flores-Ramírez N, García-González L, Zamora-Peredo L, Mondragón-Sánchez ML. Composite Films from Polystyrene with Hydroxyl end Groups and Carbon Nanotubes. Materials Research. 2016;19(Supp 1):133-138. DOI: http://dx.doi.org/10.1590/19805373-mr-2016-0783

5. Coelho PHSL, Marchesin MS, Morales AR, Bartoli JR. Electrical percolation, morphological and dispersion properties of MWCNT/PMMA nanocomposites. Materials Research. 2014;17(Suppl 1):127-132. DOI: http://dx.doi.org/10.1590/ S1516-14392014005000059

6. Shieh YT, Hsieh KC, Cheng CC. Carbon nanotubes stabilize poly(vinyl chloride) against thermal degradation. Polymer Degradation and Stability. 2017;144:221-230. DOI: http:// dx.doi.org/10.1016/j.polymdegradstab.2017.08.017

7. Broza G, Piszczek K, Schulte K, Sterzynski T. Nanocomposites of poly(vinyl chloride) with carbon nanotubes (CNT). Composites Science and Technology. 2007;67(5):890-894. DOI: http:// dx.doi.org/10.1016/j.compscitech.2006.01.033

8. Ceresana Market Intelligence. Market Study: Polyvinyl Chloride - PVC. 4(th) ed. Constance: Ceresana; 2017. p. 40-80.

9. Ceresana Market Intelligence. Global demand for PVC to rise by about 3.2\%/year to 2021. Additives for Polymers. 2014;11:1011. DOI: https://doi.org/10.1016/S0306-3747(14)70175-7

10. Araujo RG, Pires ATN. Nanocompósitos PVC/nanotubos de carbono: avaliação da resistividade elétrica e efeito do solvente utilizado na obtenção dos nanocompósitos nas propriedades térmicas. Polímeros. 2013;23:839-843. DOI: http://dx.doi. org/10.4322/polimeros.2013.072
11. Girotto EM, Santos IA. Medidas de resistividade elétrica DC em sólidos: como efetuá-las corretamente. Química Nova. 2002;25(4):639-647. DOI: http://dx.doi.org/10.1590/S010040422002000400019

12. Yu J, Sun L, Ma C, Qiao C, Yao H. Thermal degradation of PVC: A review. Waste Management. 2016;48:300-314. DOI: http://dx.doi.org/10.1016/j.wasman.2015.11.041

13. Xu X, Chen S, Tang W, Qu Y, Wang X. Investigation of basic zinc cyanurate as a novel thermal stabilizer for poly(vinyl chloride) and its synergistic effect with calcium stearate. Polymer Degradation and Stability. 2014;99:211-218. DOI: http://dx.doi.org/10.1016/j.polymdegradstab.2013.11.003

14. Yazdani H, Smith BE, Hatami K. Multi-walled carbon nanotubefilled polyvinyl chloride composites: Influence of processing method on dispersion quality, electrical conductivity and mechanical properties. Composites Part A: Applied Science and Technology. 2016;82:65-67. DOI: http://dx.doi.org/10.1016/j. compositesa.2015.12.005

15. Wang XH, Mu YH, Tang Q, Li CQ. Preparation and Performance of PVC/CNT Nanocomposite. Advances in Polymer Technology. 2018;37(2):358-364. DOI: https://doi.org/10.1002/adv.21674

16. Zanjanijam AR, Bahrami M, Hajian M. Poly(vinyl chloride)/ single wall carbon nanotubes composites: investigation of mechanical and thermal characteristics. Journal of Vinyl \& Additive Technology. 2016;22(2):128-133. DOI: http://dx.doi. org/10.1002/vnl.21413

17. Mkhabela VJ, Mishra AK, Mbianda XY. Thermal and mechanical properties of phosphorylated multiwalled carbon nanotube/ polyvinyl chloride composites. Carbon. 2011;49(2):610-617. DOI: http://dx.doi.org/10.1016/j.carbon.2010.10.006 